\title{
Temperature and melting of a ridge-centred plume with application to Iceland. Part II: Predictions for electromagnetic and seismic observables
}

\author{
A. Kreutzmann, ${ }^{1}$ H. Schmeling, ${ }^{1}$ A. Junge, ${ }^{1}$ T. Ruedas, ${ }^{1, *}$ G. Marquart ${ }^{1}{ }^{\dagger} \dagger$ \\ and I. Th. Bjarnason ${ }^{2}$ \\ ${ }^{1}$ Institute of Meteorology and Geophysics, J. W. Goethe University Frankfurt, Feldbergstr. 47, D-60323 Frankfurt am Main, Germany. \\ E-mail: akreutz@geophysik.uni-frankfurt.de \\ ${ }^{2}$ Science Institute, University of Iceland, Askja Sturlugötu, IS-101 Reykjavik, Iceland
}

Accepted 2004 June 21. Received 2004 May 11; in original form 2003 July 15

\section{S UMMAR Y}

The dynamic and melting processes of a ridge-centred plume have been investigated in a companion paper by Ruedas et al. (hereafter referred to as Paper I) in a set of 3-D numerical fluid dynamic models with varying plume excess temperatures and melt extraction thresholds. In Paper I, the modelled thickness of the generated crust has been compared to observations of the Icelandic crust. Using the results of those plume models magnetotelluric (MT) transfer functions and seismic velocity anomalies are predicted in this paper. Together with Paper I, a dynamically consistent set of geophysical observables of a ridge-centred plume is presented and applied to Iceland.

Temperature, partial melting and the connectivity of the melt phase influence the electrical conductivity of crust and mantle rocks. The temperature and melt fraction of our plume models are used to calculate 3-D conductivity models for MT modelling. For the melt geometry ellipsoidal inclusions with appropriate aspect ratios were assumed to control melt connectivity. The resulting transfer functions are compared to each other and to models not including a plume to separate signals from the ridge and the plume. They may be applied to observed MT measurements. If the plume head contains only 1 per cent of melt, the plume signal cannot be distinguished from the ridge signal, at least 3 per cent melt is needed for such distinction. The other predicted observables calculated from the different numerical models are seismic velocity anomalies. The temperature-induced $V_{P}$ and $V_{S}$ anomalies were estimated including anharmonic and anelastic effects as well as the water induced increase of dislocation mobility that lowers seismic velocities. Realistic melt geometries, as observed in laboratory experiments, were used to calculate the effect of partial melts on the seismic velocities. $V_{S}$ anomaly distributions are synthesized from the different plume models and compared to seismic observations. To reconcile seismic anomalies of the plume head and plume stem, a wet plume stem overlain by a partially molten, dehydrated plume head is favoured.

The combined interpretation of available observations, crustal thicknesses (Paper I) and seismic results, with our dynamic plume models (Paper I) leads to a favoured plume model with $135 \mathrm{~K}$ excess temperature and a vertical velocity of approximately $13 \mathrm{~cm} \mathrm{yr}^{-1}$ at $200 \mathrm{~km}$ depth, with 1 per cent melt extraction threshold, and a melting zone of approximately $500 \mathrm{~km}$ width and $100 \mathrm{~km}$ depth extent.

Key words: hotspots, Iceland plume, magnetotellurics, melt, mid-ocean ridges, seismic velocities. *Now at: Dansk Lithosfærecenter, Øster Voldgade 10 L, 1350 Copenhagen
K, Denmark. $\dagger$ Now at: Space Research Organization Netherlands \& University of Utrecht, PO Box 80021, 3508 TA Utrecht, the Netherlands. 


\section{INTRODUCTION}

A ridge-centred hotspot such as Iceland is characterized by extensive volcanism and correspondingly highly anomalous crust production (e.g. White \& McKenzie 1995). However, rock parameters such as the electrical conductivity or the seismic velocity do not show comparably dramatic anomalies (Beblo et al. 1983; Wolfe et al. 1997). A combined approach is necessary to reconcile the dynamics and melting processes of a ridge-centred plume with observable structural parameters. In a companion paper (Ruedas et al. 2004), hereafter called Paper I, we investigated the dynamics and melting processes of a ridge-centred plume by numerical modelling. Depending on critical parameters, such as the excess temperature of the plume or the melt extraction threshold, crustal production rates have been modelled, resulting in crustal thicknesses of large variability. The estimated crustal thicknesses from seismic and gravity observations (e.g. Darbyshire et al. 2000) imposed constraints on the dynamic plume parameters (Paper I). Using the dynamically consistent models of Paper I, this paper aims at the prediction of magnetotelluric (MT) transfer functions and anomalous seismic velocities. The predicted values may then be compared to observations and will be used for joint interpretations of seismic, MT and crustal thickness data. As such predictions will be carried out for a variety of different dynamic plume parameters, they may also provide important tools for interpretations of geophysical observables of other plumes.

The structure beneath Iceland has been investigated using MTs (Beblo \& Björnsson 1978, 1980; Beblo et al. 1983; Hersir et al. 1984; Eysteinsson \& Hermance 1985), seismology (Wolfe et al. 1997; Bijwaard \& Spakman 1999; Ritsema et al. 1999; Foulger et al. 2001; Rhodes \& Davies 2001; Allen et al. 2002) and seismics and gravity (see Darbyshire et al. 2000). MT signals are controlled by the electrical conductivity distribution, which is a strong function of the temperature, melt fraction and melt connectivity (Schmeling 1986; Roberts \& Tyburczy 1999). Seismic velocities depend on these properties in a different way (e.g. Schmeling 1985b; Karato 1993; Takei 2000), thus joint interpretations of these observables can increase our knowledge about thermally anomalous regions. In an early first attempt, Schmeling (1985a) tried to apply this approach to seismic and electric data of Iceland. However, at that time, the thickness of the Icelandic crust was not yet known and seismic tomography models of the plume hardly existed (see Tryggvason et al. 1983). Furthermore, the electrical conductivity data were based on relatively short period MT observations, restricting the depth resolution to the crust. During the last decade a broad discussion has been triggered about the thickness of the Icelandic crust and the existence of the plume: seismic tomography has been developed extensively (Wolfe et al. 1997; Foulger et al. 2001; Allen

(a)

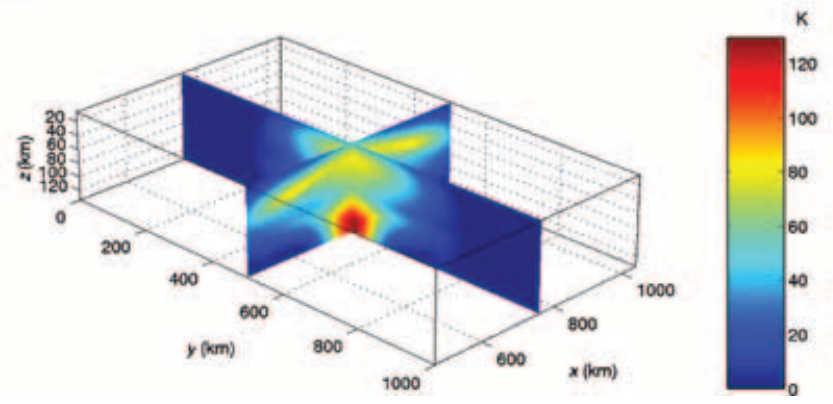

et al. 2002) and long-period MT measurements have been carried out (König 1999; Salat 2002). Thus new and better results give rise to an improved geodynamic modelling. In the following, we will establish a set of dynamically consistent plume observables. As a first step, dynamic models of a rising ridge-centred plume with melting and melt extraction are developed. They are discussed in detail in Paper I, a short summary is given in Section 2. To relate results from the geodynamic models, such as temperature and melt fraction, to geophysical observables, rock physics relations are compiled and derived in Section 3. Using these relations, distributions of the electrical conductivity and seismic velocities of different dynamic plume models are presented in Section 4. The predictions will be discussed together with the results of the crustal thickness of Paper I. Comparing the model results to existing observations, a plausible plume model will be derived from which future observations can be estimated.

\section{DYNAMIC MODELS}

Melting in a ridge-centred plume has been studied in Paper I using 3-D geodynamic modelling. In a model box of $660 \mathrm{~km}$ depth, the equations of conservation of mass, momentum and energy have been solved for a two-phase solid-melt system with the viscosity depending on temperature and depth. While the plume was initiated at the bottom of the model by prescribing the plume influx with a volume flux of $1.45 \mathrm{~km}^{3} \mathrm{yr}^{-1}$ (for a detailed discussion of the volume flux and comparison with previous estimate see Paper I) and a certain excess temperature $\Delta T_{\mathrm{P}}$ in $200 \mathrm{~km}$ depth, the kinematic boundary condition at the surface represents a ridge with a half spreading rate of $1 \mathrm{~km}^{3} \mathrm{yr}^{-1}$. When the melt exceeds a given critical value $\varphi_{\mathrm{ex}}$, it is removed from the interior and put on top of the model increasing the thickness of the crust. The potential temperature of the mantle was assumed to be $1410{ }^{\circ} \mathrm{C}$, see Paper I for more details. A dynamic plume reference model (DPRM) was defined by $\Delta T_{\mathrm{P}}=135 \mathrm{~K}$ and $\varphi_{\mathrm{ex}}=0.01$. As an example, Fig. 1(a) shows the anomalous temperature field of that plume, with respect to the normal spreading ridge area, and the resulting melt fraction. It should be noted that the temperature anomaly within the plume head is considerably reduced as a result of cooling by consumption of the latent heat of melting. As can be seen in Fig. 1(b), melt fractions of approximately 1 per cent are present both in the normal spreading region and in a much larger region within the plume head. The plume parameters $\Delta T_{\mathrm{P}}$ and $\varphi_{\mathrm{ex}}$ were varied independently, yielding a set of dynamic models. Depending on these parameters, the resulting crustal thickness $h$ was estimated for (near) steady state conditions. The models and the main results of Paper I are summarized in Table 1. From these results it becomes clear that only slight

\section{(b)}

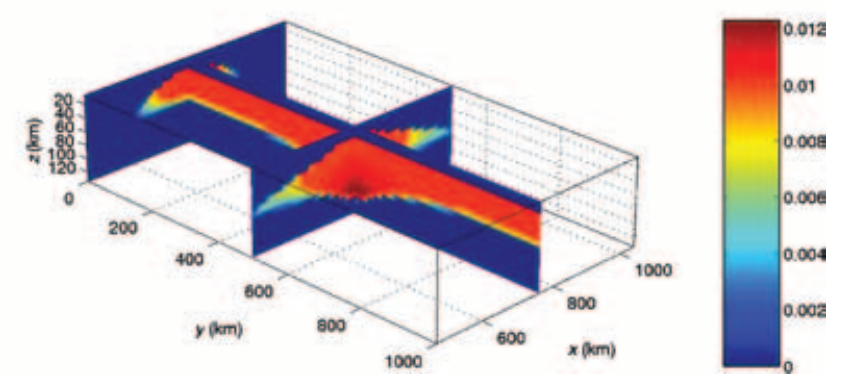

Figure 1. Dynamic plume reference model (DPRM): (a) temperature anomaly $T(x, y, z)-T(x, 0, z)$ in melting grid (in $\mathrm{K}$ ); (b) melt fraction before extraction in melting grid. Ridge axis in $y$ direction, see Paper I. 
Table 1. Model results from Paper I. $h_{\max }$ is the maximum crustal thickness, $z_{\text {sol }}$ is the depth where the solidus is reached. The excess temperature at the solidus depth, $\Delta T_{\mathrm{P}}\left(z_{\mathrm{sol}}\right)$, is taken at the centre line of the plume. The maximum values of the plume velocity, $v_{z}$, are estimated averages of the steady state. Model names denote plume excess temperature $\Delta T_{\mathrm{P}}$ and melt extraction threshold $\varphi_{\text {ex }}$.

\begin{tabular}{lcccc}
\hline Model & $h_{\max }(\mathrm{km})$ & $z_{\text {sol }}(\mathrm{km})$ & $\Delta T_{\mathrm{P}}\left(z_{\text {sol }}\right)(\mathrm{K})$ & $\max . v_{z}\left(\mathrm{~cm} \mathrm{yr}^{-1}\right)$ \\
\hline Plume centre & & & & \\
DPRM (135-1) & 49 & 110 & 115 & 17 \\
$220-1$ & 119 & 133 & $\sim 180$ & 22 \\
$50-1$ & 15 & 85 & $\sim 40$ & 11 \\
$135-0.1$ & 54 & 110 & 115 & $\sim 16$ \\
$135-3$ & 27 & 110 & 115 & 16 \\
$135-100$ & n.d. & 110 & 115 & $\sim 16$ \\
Normal ridge & & & & \\
$\varphi_{\text {ex }}$ 1 per cent & 5.6 & 75 & - & $\sim 1$ \\
$\varphi_{\text {ex }}$ 0.1 per cent & 7.7 & 75 & - & $\sim 1$ \\
$\varphi_{\text {ex }}$ 3 per cent & 0 & 75 & - & $\sim 1$ \\
\hline
\end{tabular}

Table 2. Variables used in this paper; for unlisted variables, see Paper I.

\begin{tabular}{llr}
\hline$\alpha$ & Thermal expansivity & $\mathrm{K}^{-1}$ \\
$\gamma_{\mathrm{D}}$ & Debye-Grüneisen parameter & 1.26 \\
$\omega$ & Seismic angular frequency & $\mathrm{Hz}$ \\
$\phi$ & MT phase & $\circ$ \\
$\rho$ & Resistivity & $\Omega \mathrm{m}$ \\
$\rho_{\mathrm{a}}$ & MT apparent resistivity & $\Omega \mathrm{m}$ \\
$\underline{B}$ & Magnetic field & $\mathrm{T}$ \\
$C_{V}$ & Specific heat at constant volume & $\mathrm{J} \mathrm{kg}^{-1} \mathrm{~K}^{-1}$ \\
$E$ & Electric field & $\mathrm{V} \mathrm{m}^{-1}$ \\
$E_{\sigma}$ & Activation energy for electrical & $\mathrm{J}$ \\
& conductivity & \\
$E_{Q}$ & Activation energy for attenuation & $\mathrm{J} \mathrm{mol}^{-1}$ \\
$k_{\mathrm{B}}$ & Boltzmann constant & $\mathrm{GPa}^{-1}$ \\
$K_{T}$ & Isothermal bulk modulus & $\mathrm{GPa}^{-1}$ \\
$p$ & Pressure & \\
$Q^{-1}$ & Attenuation & $8.6173 \cdot 10^{-5} \mathrm{eV} \mathrm{K}^{-1}$ \\
$R$ & Universal gas constant & $\mathrm{K}$ \\
$\bar{T}$ & Absolute temperature & $\mathrm{m} \mathrm{s}^{-1}$ \\
$V_{P}$ & $P$-wave velocity & $\mathrm{m} \mathrm{s}^{-1}$ \\
$V_{S}$ & $S$-wave velocity & $\mathrm{km} \mathrm{s}^{-1}$ \\
$\underline{\mathbf{Z}}$ & Impedance tensor & $8.314 \mathrm{~J} \mathrm{~mol}^{-1}$ \\
\hline
\end{tabular}

variations in plume parameters may lead to large variations in crustal thicknesses. A typical value for the thickness of the anomalous Icelandic crust is approximately 30 to $40 \mathrm{~km}$. Table 1 suggests that the DPRM as well as plumes with either higher $\Delta T_{\mathrm{P}}$ and higher $\varphi_{\mathrm{ex}}$ or lower $\Delta T_{\mathrm{P}}$ and lower $\varphi_{\mathrm{ex}}$ may roughly explain the observed Icelandic crustal thicknesses. However, as discussed in Paper I, models with high $\varphi_{\text {ex }}$ fail to produce a reasonable normal oceanic crust. In the following, further constraints on the dynamic and melting parameters will be obtained by invoking additional observables such as the electrical conductivity and the seismic velocities. This will be achieved by using the 3-D temperature and melt fraction fields of the dynamic models listed in Table 1 together with the rock physics relations derived in the following section. The variables used in this paper are summarized in Table 2 .

\section{ROCK PHYSICS RELATIONS}

The electrical conductivity, seismic velocity and attenuation depend on different thermodynamic and melting parameters. In this respect the temperature, melt fraction and melt connectivity are most important. Pressure effects are generally small, compositional effects might be large, but here we start from the assumption of an initially compositional homogeneous plume and are interested in the anomalous quantities. In the following, we describe the physical expressions used to convert the parameters of the geodynamic plume models into observable field values.

\subsection{Electrical conductivity}

In this section we describe the method used to calculate the spatial distribution of the effective electrical conductivity from a 3-D temperature and melt fraction field provided by the dynamic models. The temperature dependence of the electrical conductivity of solid mantle rock is given by the Arrhenius relation based on laboratory experiments with olivine (Shankland \& Waff 1977; Constable et al. 1992):

$\sigma_{\mathrm{s}}=\sigma_{0} \exp \left(-\frac{E_{\sigma}}{k_{\mathrm{B}} \bar{T}}\right)$,

where $E_{\sigma}=1.5 \mathrm{eV}$ is the activation energy, $k_{\mathrm{B}}$ is the Boltzmann constant, $\bar{T}$ is the absolute temperature and $\sigma_{0}=150 \mathrm{~S} \mathrm{~m}^{-1}$ is the asymptotic high temperature conductivity. The electrical conductivity as a function of temperature for basaltic melts has been measured by Waff \& Weill (1975) and Tyburczy \& Waff (1983). It is characterized essentially by an Arrhenius relationship similar to that of solid olivine, but shifted to significantly higher values. A good approximation for the conductivity of the melt is $\sigma_{\mathrm{f}}=\sim 400 \cdot \sigma_{\mathrm{s}}$. The effective conductivity of partially molten peridotite has been measured in the laboratory by several authors [Berckhemer et al. 1982; Tyburczy \& Waff 1983; Roberts \& Tyburczy 1999; Maumus et al. 2004]. However, it is difficult to separate the influence of temperature, melt fraction, oxygen fugacity and composition from these measurements. To explain the application of an extraction threshold, a model with a reduced degree of connectivity is necessary. Therefore, we use a theoretical model of the effective conductivity of a two-phase system (Schmeling 1986).

If $P(0 \leq P \leq 1)$ is the connectivity of the melt (see appendix A for the exact definition and further details), a good approximation of the effective conductivity $\sigma_{\text {eff }}$ for reduced connectivity is the geometric mean [i.e. the arithmetic mean of the logarithms weighted with $P$ and $(1-P)]$ :

$\sigma_{\mathrm{eff}}=\sigma_{\mathrm{HS}+}^{P} \cdot \sigma_{\text {iso }}^{1-P}$,

where $\sigma_{\mathrm{HS}+}$ is the upper Hashin-Shtrikman bound and $\sigma_{\text {iso }}$ is the conductivity of a system with isolated melt inclusions. Eq. (2) has been empirically verified for resistor network models (Madden 1976). For a particular aspect ratio, the $T$ - and $\varphi$-dependent electrical conductivity can be calculated by eq. (2). The question arises which aspect ratio should be used for the particular plume models. In the dynamic plume models, different extraction thresholds $\varphi_{\mathrm{ex}}$ were taken. As the melt for $\varphi>\varphi_{\mathrm{ex}}$ is extracted, the system has the state of perfect connectivity for $\varphi=\varphi_{\text {ex }}$. This condition corresponds to $P=1$ or $N=N_{\max }=4$. Thus, inserting $\varphi_{\mathrm{ex}}$ and $N_{\max }$ into eq. (A2) (see Appendix) we can determine the corresponding aspect ratio $\mathcal{A}$. This procedure resulted in aspect ratios for the different extraction thresholds summarized in Table 3 . The model without melt extraction contains a maximum melt fraction of 28 per cent; thus, this value was used for determining the corresponding aspect ratio. As an example, the resulting relation between the effective conductivity and temperature including variable melt fractions is shown in Fig. 2(a) for batch melting and in Fig. 2(b) for three different values of $\varphi_{\text {ex }}$. In this figure, the temperature dependent melt fraction has been taken from the melting model used for the dynamic plume (see 
Table 3. Aspect ratio $\mathcal{A}$ as a function of the melt extraction threshold $\varphi_{\text {ex }}$.

\begin{tabular}{ll}
\hline$\varphi_{\text {ex }}($ per cent $)$ & $\mathcal{A}$ \\
\hline 0.1 & 0.00043 \\
1 & 0.00436 \\
3 & 0.01347 \\
No extraction & $>0.23$ \\
\hline
\end{tabular}

Paper I for details) at a pressure of $1.7 \mathrm{GPa}$ (corresponding to around $50 \mathrm{~km}$ depth). In Figs 2(a) and (b), one can clearly identify the subsolidus part of the curve (to the right of the rectangle, representing eq. (1), the partially molten part for different aspect ratios (within the rectangle, $c f$. eq. (2) and the Hashin-Shtrikman curve (straight lines to the left of the rectangle, $c f$. eq. A4 in the Appendix). On the right-hand side of Figs 2(a) and (b) the magnified middle parts (rectangles) of these curves are shown to identify the differences between the curves. It should be noted that in Fig. 2 a unique relation between temperature and melt fraction has been used (batch melting), while in the following models temperature and melt fraction have to be considered separately because of melt extraction.

As a result of the melting process, the solid rock residues are depleted in certain minerals. In the following discussion, we estimate the effect of mantle rock iron depletion on the electrical conductivity. In Tyburczy \& Fisler (1995), the conductivity-temperature dependency for olivines of different compositions is shown. For $\mathrm{Fo}_{80}$ and $\mathrm{Fo}_{90}$ it is $\log _{10} \sigma_{\mathrm{s}}^{\mathrm{Fo} 80}-\log _{10} \sigma_{\mathrm{s}}^{\mathrm{Fo} 90}=1.2$. Hence,

$\frac{\partial \log _{10} \sigma_{\mathrm{s}}}{\partial \mathrm{Mg} \#} \approx \frac{\Delta \log _{10} \sigma_{\mathrm{s}}}{\Delta \mathrm{Mg} \#}=-12$, where $\mathrm{Mg} \#$ is the $\mathrm{Mg}$ number. Because iron-rich phases melt first, the melting process is characterized by a decreasing Fe number:

$\mathrm{Fe} \#=\frac{X_{\mathrm{Fe}}}{X_{\mathrm{Fe}}+X_{\mathrm{Mg}}}$

and $\mathrm{Mg} \#=1-$ Fe\#. From Jordan $(1979$, table 6$)$ it is possible to deduce

$$
\frac{\partial \mathrm{Fe} \#}{\partial f}=-0.12 \Rightarrow \frac{\partial \mathrm{Mg} \#}{\partial f}=+0.12 \text {, }
$$

where $f$ is the degree of melting (or depletion). With this, we can write the variation of $\log _{10} \sigma_{\mathrm{s}}$ with the degree of melting $f$ :

$\frac{\partial \log _{10} \sigma_{\mathrm{s}}}{\partial f}=\frac{\partial \log _{10} \sigma_{\mathrm{s}}}{\partial \mathrm{Mg} \#} \cdot \frac{\partial \mathrm{Mg} \#}{\partial f}=-12 \cdot 0.12=-1.44$.

To find the variation of $\log _{10} \sigma_{\mathrm{s}}$ with temperature:

$\frac{d \log _{10} \sigma_{\mathrm{s}}}{d T}=\frac{\partial \log _{10} \sigma_{\mathrm{s}}}{\partial f} \cdot \frac{d f}{d T}+\frac{\partial \log _{10} \sigma_{\mathrm{s}}}{\partial T}$.

The second term is equal to $d \log _{10} \sigma_{\mathrm{s}_{\mathrm{old}}} / d T$, where $\sigma_{\mathrm{s}_{\text {old }}}$ is the conductivity for olivine calculated from eq. (1). We additionally need the derivative $d f / d T$, which we obtain by differentiating the equation that describes the dependency $f(T)$ given by McKenzie \& Bickle (1988, eq. 21). This yields

$\frac{d f}{d T}=\frac{1}{T_{1}-T_{\mathrm{s}}}\left(1-0.25 a_{1}+2 a_{0} T^{\prime}+3 a_{1} T^{\prime 2}\right)$,

with $a_{0}=0.4256, a_{1}=2.988$ and

$T^{\prime}=\frac{T-\left[\left(T_{\mathrm{s}}+T_{1}\right) / 2\right]}{T_{1}-T_{\mathrm{s}}}$
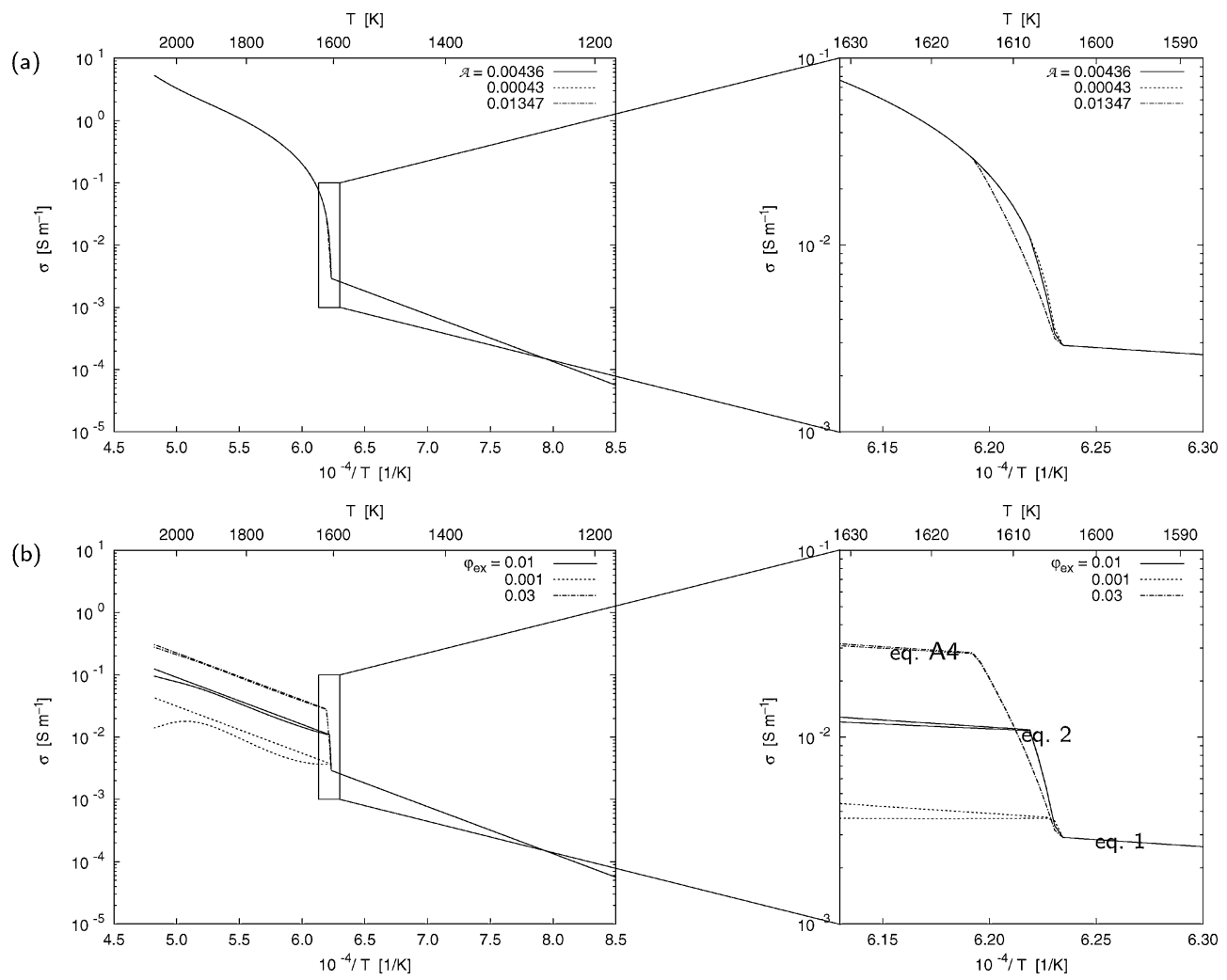

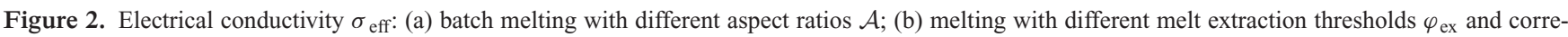
sponding aspect ratios $\mathcal{A}$ ( $c f$. Table 3 ). For every $\varphi_{\mathrm{ex}}$ there are two curves, whereby the lower undulating curve, respectively, shows the case including mantle rock depletion. In the magnified middle parts of these curves on the right-hand side, the different states of melting (solid, partially molten with reduced connectivity, Hashin-Shtrikman conditions) are marked with the corresponding equations. For further explanation see text. 
(McKenzie \& Bickle 1988), where $T_{\mathrm{s}}$ and $T_{1}$ are the solidus and liquidus temperatures, respectively, defined in Paper I. Now we can rewrite eq. (3):

$$
\begin{aligned}
\frac{d \log _{10} \sigma_{\mathrm{s}}}{d T}= & -1.44 \frac{1}{T_{1}-T_{\mathrm{s}}}\left(1-0.25 a_{1}+2 a_{0} T^{\prime}+3 a_{1} T^{\prime 2}\right) \\
& +\frac{d \log _{10} \sigma_{\mathrm{s} \text { old }}}{d T} .
\end{aligned}
$$

Integration yields an approximative formula:

$\sigma_{\mathrm{s}}(T)=\sigma_{\mathrm{s}_{\text {old }}} \cdot 10^{-1.44 \frac{1}{T_{1}-T_{\mathrm{s}}}\left(1-0.25 a_{1}+2 a_{0} T^{\prime}+3 a_{1} T^{\prime 2}\right)\left(T-T_{\mathrm{s}}\right)}$.

The new values for $\sigma_{\mathrm{s}}$ were used to calculate new values for the conductivity $\sigma_{\mathrm{HS}+}$ that take into account depletion. The resulting relations between conductivity and temperature are also shown in Fig. 2(b) for three different values of $\varphi_{\text {ex }}$. These curves run beneath the lines for the case without depletion for temperatures above the solidus. For $\varphi_{\mathrm{ex}}=0.1$ per cent the curve undulates and the difference to the normal curve is substantial. For increasing $\varphi_{\text {ex }}$, the undulations and differences decrease so that for $\varphi_{\mathrm{ex}}=3$ per cent the discrepancies are negligible.

\subsection{Seismic velocities}

Seismic velocities depend on pressure, temperature, melt fraction and composition (e.g. Sobolev et al. 1996; Goes et al. 2000). Typical pressure-dependent variations of $V_{P}$ and $V_{S}$ at dynamic pressures of the order of $10 \mathrm{MPa}$ are of the order 0.01 per cent or less and therefore they are neglected. The dependence of seismic velocities on lithostatic pressure is eliminated by taking the velocities with respect to a reference velocity profile. Following Karato (1993), the temperature influence is separated into an anharmonic and an anelastic contribution. For temperature deviations $\delta T(x, y, z)=$ $T(x, y, z)-T_{\text {ref }}(z)$ (here $T_{\text {ref }}(z)$ is a reference temperature profile, taken for a 20 Myr old lithosphere), the velocity variation $\delta V$ hspace$1.5 \mathrm{pt}_{P, S}(x, y, z)=V_{P, S}(x, y, z)-V_{P, S \text { ref }}(z)$ can be written as

$$
\begin{aligned}
\frac{\delta V_{P, S}}{V_{P, S}}=\left(\frac{\partial \ln V_{P, S}}{\partial \bar{T}}\right)_{\text {anh }} \delta T \\
\quad-\frac{1}{2} \cot \left(\frac{\pi q}{2}\right)\left[Q_{P, S}^{-1}(T)-Q_{P, S}^{-1}\left(T_{\text {ref }}\right)\right],
\end{aligned}
$$

where $Q_{P, S}^{-1}$ is the seismic absorption for $P$ and $S$ waves, respectively, which has the form (Jackson et al. 2000)

$Q^{-1}=A a^{-m} \omega^{-q} \exp \left(-\frac{q E_{Q}}{R \bar{T}}\right)$.

$A$ is a pre-exponential factor, $a$ is the grain size, $m$ is the power of the grain size dependence, $\omega$ is the seismic angular frequency, $q$ is the power of the frequency dependence of $Q, E_{Q}$ is the activation energy and $R$ is the gas constant. For typical upper-mantle conditions and neglecting bulk attenuation, we have $Q_{P}^{-1}=0.4 Q_{S}^{-1}$. Following Karato (1993), the first term of eq. (5) is

$\left(\frac{\partial \ln V_{P, S}}{\partial \bar{T}}\right)_{\text {anh }}=-\left(\frac{\partial \ln V_{P, S}}{\partial \ln \varrho}\right)_{p} \alpha$,

where $\alpha$ is the thermal expansivity and $\varrho$ is the density. From experimental determinations $\left(\partial \ln V_{P} / \partial \ln \varrho\right)_{p}=2.1$ and $\left(\partial \ln V_{S} /\right.$ $\partial \ln \varrho)_{p}=2.5$ (Christensen 1989). The depth dependence of eq. (7) can be approximated from thermodynamic relations by

$\alpha(z)=\frac{\gamma_{\mathrm{D}} C_{V} \varrho_{0}}{K_{T 0}\left(1+c_{1} z+c_{2} z^{2}\right)}$, where $\gamma_{\mathrm{D}}=1.26$ is the Debye-Grüneisen parameter, $C_{V}=$ $1250 \mathrm{~J} \mathrm{~kg}^{-1} \mathrm{~K}^{-1}$ is the specific heat at constant volume, $\varrho_{0}=$ $3500 \mathrm{~kg} \mathrm{~m}^{-3}$ is the reference density, $K_{T 0}=129 \mathrm{GPa}$ is the isothermal bulk modulus at the surface, $z$ is the depth and $c_{1}=4.133$. $10^{-7} \mathrm{~m}^{-1}, c_{2}=1.18 \cdot 10^{-12} \mathrm{~m}^{-2}$ are parameters derived from fitting a second-order polynomial of $K_{T} / \varrho$ to PREM within the depth interval 25 to $660 \mathrm{~km}$. Eqs (7) and (8) show that the temperature dependence of $V_{P, S}$ becomes weaker with increasing depth.

The anelastic contribution can be determined from experimental $Q$ measurements on polycrystalline olivine using $A=12.6 \mathrm{~m}^{m} \mathrm{~s}^{-q}$, $m=0.33, q=0.25, E_{Q}=430 \mathrm{~kJ} \mathrm{~mol}^{-1}$ (Jackson et al. 2000), as well as typical grain sizes of $a=0.001-0.01 \mathrm{~m}$ and seismic frequencies of $\omega /(2 \pi)=22-0.1 \mathrm{~Hz}$, respectively. The pressure dependence of $Q$ has not been determined up to now except for ultrasonic waves up to a pressure of $730 \mathrm{MPa}$ (30 km depth; Sato et al. 1989). Nevertheless, extrapolation to greater depths (pressures) is done by normalizing $Q$ to its value at the melting temperature of $\mathrm{Fo}_{90}$ and accounting for the pressure dependence of $Q$ along the solidus temperature $T_{\mathrm{s}}(p)$, $Q\left[T=T_{\mathrm{s}}(p)\right]=Q\left[T=T_{\mathrm{s}}(0)\right]+p / p_{0}$, (Sato et al. 1989). It should be noted that the solidus temperature of olivine ( 90 per cent $\mathrm{Mg}, 10$ per cent $\mathrm{Fe}$ ) is used because the $Q$ data are based on olivine. Thus, for a given $p, T$, the normalized temperature $\hat{T}=T / T_{\mathrm{s}}(p)$ is determined and the extrapolated $Q_{\text {ext }}$ is obtained from

$Q_{\text {ext }}(p, T)=Q(p=0, \hat{T}) \frac{Q(p=0, \hat{T}=1)+p / p_{0}}{Q(p=0, \hat{T}=1)}$.

The parameter $p_{0}$ describing the pressure dependence is adjusted to fit an observed $Q$ profile (Widmer et al. 1991) for a reference temperature distribution. The best fit was obtained for $p_{0}=1 \mathrm{GPa}$.

Based on the formulation above, Fig. 3 show maps of temperatureinduced $V_{P}$ and $V_{S}$ anomalies as a function of depth and temperature. Along the reference temperature profile the velocity anomaly is 0 , of course. At $100 \mathrm{~km}$ depth, $V_{S}$ and $V_{P}$ variations are approximately -1 per cent per 64 and $94 \mathrm{~K}$, and near $300 \mathrm{~km}$ depth we have -1 per cent per 95 and $123 \mathrm{~K}$, respectively. Thus a plume with $200 \mathrm{~K}$ excess temperature should be seen approximately as a -3 and -2 per cent $V_{S}$ and $V_{P}$ anomaly at $100 \mathrm{~km}$ depth, and at $300 \mathrm{~km}$ depth as a -2.1 and -1.6 per cent $V_{S}$ and $V_{P}$ anomaly, respectively.

The effect of partial melts on the seismic velocities has been investigated by a number of studies. In most studies, the geometrical distribution of melt has been assumed by mathematically idealized shapes (O’Connell \& Budiansky 1977; Mavko 1980; Schmeling 1985b). In the model of Takei (1998), the effective moduli are based on grain boundary contiguity and thus relate to the dihedral angle between melt and solid grains. This model could be verified by laboratory measurements (Takei 2000). Only a few studies used realistic partial melt geometries (Zippel 1996; Hammond \& Humphreys 2000). In the numerical models of Zippel (1996), realistic melt geometries have been taken from photographs of thin sections of partially molten peridotite with various melt fractions (Faul 1997). These photographs have been transformed into 2-D purely elastic finite element grids, assuming different bulk moduli (66, $20 \mathrm{GPa})$ for matrix and melt, as well as different shear moduli (40, $0 \mathrm{GPa}$, respectively). These setups have been subjected to external compression and shear, and the effective moduli have been calculated for the different melt fractions. The moduli decrease roughly linearly as the melt fraction increases. From these effective moduli, seismic velocities could be calculated as a function of melt fraction $\varphi$ only (i.e. for constant temperature), giving

$\left(\frac{\partial \ln V_{P}}{\partial \varphi}\right)_{T}=-1.23, \quad\left(\frac{\partial \ln V_{S}}{\partial \varphi}\right)_{T}=-2.04$. 

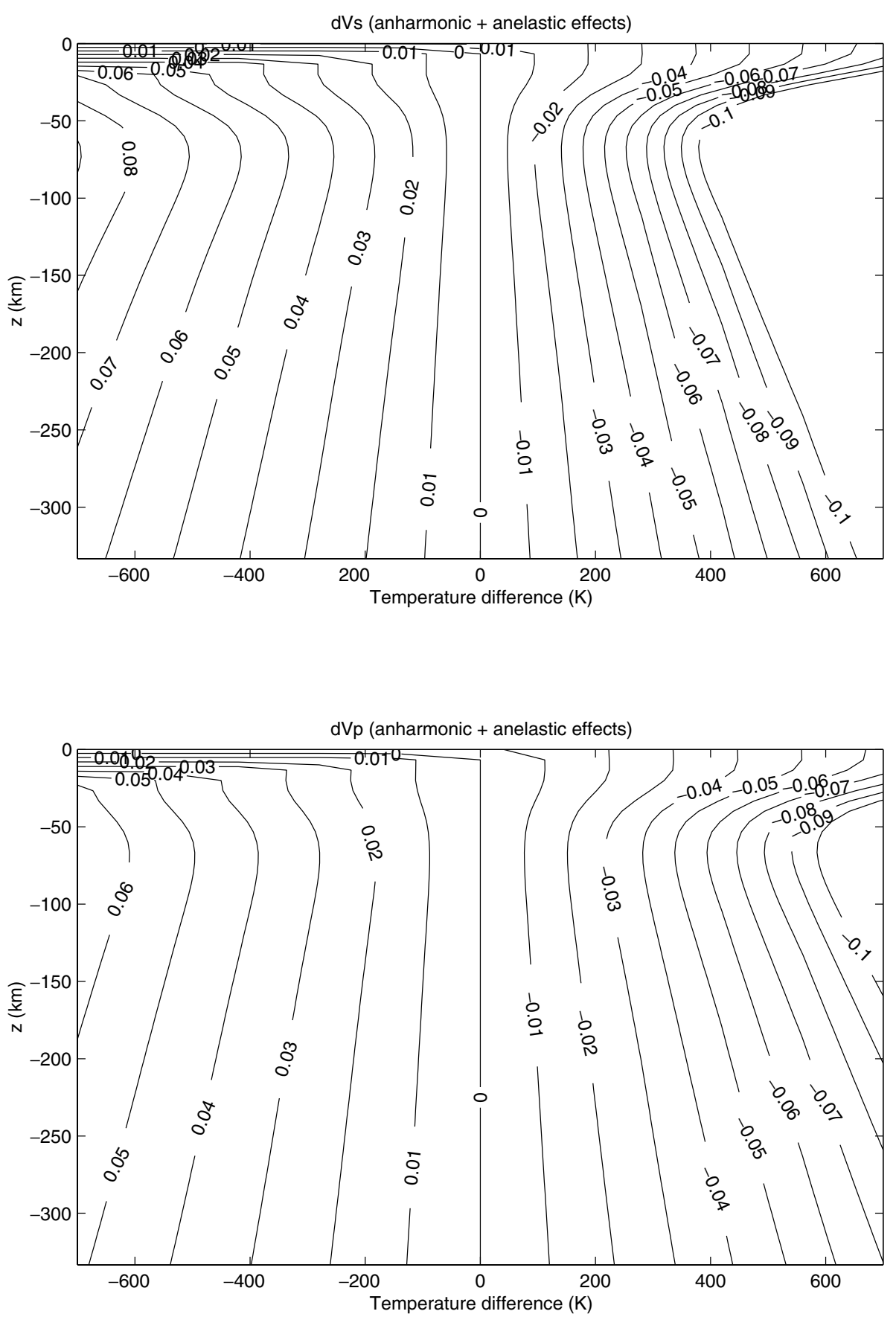

Figure 3. $\delta V_{P, S}(z, T)$ resulting from anharmonic and anelastic effects along different temperature profiles, relative to the 20-Ma-lithosphere reference profile.

To first order, these velocities represent the unrelaxed state. While these decreases are smaller than those of Hammond \& Humphreys (2000), they agree well with the model and laboratory results of Takei $(1998,2000)$, if a dihedral angle typical for the olivine-melt system is used.

\section{PREDICTED GEOPHYSICAL O BSER VA B LES}

Using the temperature and melt fraction fields obtained in the dynamic models of Paper I ( $c f$. Table 1) together with the rock physics relations of the previous section, we now calculate synthetic fields of electrical conductivity and seismic velocity anomalies of the different plume models. Starting from the DPRM, we explore the parameter space in terms of observables in two directions: models 135-0.1, 135-3 and 135-100 show the effect of different extraction thresholds on MT and seismic observables, while models 50-1 and 220-1 describe the effect of different plume excess temperatures.

As we are interested in the seismic anomalies and the MT transfer functions of a well-developed plume, we have to compare our model plumes at appropriate model times. The model times are chosen in such a way that the crustal production rate has reached a rather steady value, which corresponds to stages at which the crustal thickness curves (see Paper I) have flattened out (i.e. 10 to 20 Myr after plume arrival). 


\subsection{Electrical conductivity and magnetotelluric transfer functions}

In this section we will first determine and discuss the electrical conductivity distribution for the different plume models and then calculate the MT transfer function for a synthetic magnetic source field to decide if and under which conditions MT observations are sensitive to ridge-centred mantle plumes.

\subsubsection{Electrical conductivity distribution}

According to the discrete geodynamic models, there is a 3-D set of temperature and melt fraction values. Using eqs (1) to(2), a corresponding set of values for the effective electrical conductivity $\sigma_{\text {eff }}$ (corresponding to effective resistivity $\rho_{\text {eff }}$ ) is calculated. As the discretization of the geodynamic models is different from that of the MT models, the values have to be mapped into the new model cells. The finite difference code used for MT modelling (Mackie et al. 1994) demands a high number of cells to represent fine resolution in the vicinity of high conductivity contrasts or strong gradients. In the case of Iceland, the contrast between the conductivity of sea water $\left(4 \mathrm{~S} \mathrm{~m}^{-1}\right)$ and land $\left(0.001 \mathrm{~S} \mathrm{~m}^{-1}\right)$ therefore dominates the model design. Fig. 4(a) shows the gridding and the model resistivity distribution for the upper $1.5 \mathrm{~km}$ of the Icelandic plateau: the thick black lines (which are just a number of thin lines beneath graphical resolution) reflect the transition between sea and land, thus marking the coast of the island. The shape of Iceland is simplified forming three adjacent rectangles with high resistivity. The three horizontal sections at different depths $(0,0.9$ and $1.5 \mathrm{~km})$ have different resistivities referring roughly to the bathymetry, which is increased stepwise from 200 to $1500 \mathrm{~m}$ around the island. The total number of cells in the $x$ and $y$ direction is 139 and 133, respectively, with the $y$-axis parallel to the ridge. Iceland itself extends $400 \mathrm{~km}$ in the $x$ direction and $250 \mathrm{~km}$ (360 km including the peninsula in the northwest) in the $y$ direction. The geodynamic data sets were projected onto the MT grid for depths greater than $6.67 \mathrm{~km}$. In the low temperature region of the uppermost crust, the resistivity is limited by a maximum value of $1000 \Omega \mathrm{m}$, which is a well established value for basaltic upper crustal rocks. Beneath that depth, the resistivity varies according to the temperature and melt fraction of the geodynamic models. Figs 4(b) to (e) show the resistivity distribution of the reference model DPRM and three other dynamic models; note that only the innermost part of the models are shown to concentrate on the effect of the plume.

The resistivity distribution $\rho$ of the reference model DPRM (with $\Delta T_{\mathrm{P}}=135 \mathrm{~K}$ and melt extraction threshold $\varphi_{\mathrm{ex}}=0.01$; Fig. $4 \mathrm{~b}$ ) is shown for a vertical section along the ridge axis and two sections perpendicular to it, one crossing the plume and the other crossing the ridge far from the plume. In a $100-\mathrm{km}$-wide zone along the ridge axis, the resistivity in the upper $60 \mathrm{~km}$ is strongly reduced by a factor of approximately 0.1 compared with that of normal mantle. Below $60 \mathrm{~km}$ depth, the thermal gradient flattens and normal mantle resistivities are reached at a depth of approximately $80 \mathrm{~km}$. The presence of the plume widens this area. In the central part of the plume, where the melt fraction reaches or is close to the threshold value, the resistivity is additionally reduced down to a value of approximately 20 to $30 \Omega \mathrm{m}$ compared with approximately $200 \Omega \mathrm{m}$ at the same depth below the normal ocean ridge. Models with a lower plume excess temperature $\left(\Delta T_{\mathrm{P}}=50 \mathrm{~K}, \varphi_{\mathrm{ex}}=0.01\right)$ and $/$ or a lower melt fraction threshold $\left(\Delta T_{\mathrm{P}}=135 \mathrm{~K}, \varphi_{\mathrm{ex}}=0.001\right)$ do not show such a central region of reduced resistivity and thus do not vary strongly from normal ridge conditions (Fig. 4c). If the melt frac- tion threshold is higher $\left(\Delta T_{\mathrm{P}}=135 \mathrm{~K}, \varphi_{\mathrm{ex}}=0.03\right)$, resistivities as low as 10 to $20 \Omega \mathrm{m}$ prevail between 50 and $110 \mathrm{~km}$ depth in a 125-km-wide region (Fig. 4d). For an increased $\Delta T_{\mathrm{P}}\left(\Delta T_{\mathrm{P}}=\right.$ $\left.220 \mathrm{~K}, \varphi_{\mathrm{ex}}=0.01\right)$, the region with $\rho=20 \Omega \mathrm{m}$ expands in all directions. The model with the lower background temperature shows nearly no changes in the resistivity distribution. If no melt extraction is allowed, the maximum degree of partial melt reaches 28 per cent: under these conditions the shape of the low-resistivity region broadens dramatically and stretches out under large parts of the adjacent ridge (Fig. 4e).

\subsubsection{Magnetotelluric transfer functions}

MT transfer functions at a field site depend on the conductivity distribution underneath; thus model studies serve to find out under which conditions a plume might be detected by MT observations. In this paper, a 3-D FD code (Mackie et al. 1994) is used to evaluate model transfer functions for plane wave excitation. Deviations from the plane wave approximation are frequently observed at high latitudes and will usually decrease the influence of conductivity anomalies. As usual, the transfer functions are derived in the frequency domain from the complex Fourier transform of the horizontal electric $\underline{E}$ and magnetic $\underline{B}$ fields by a bivariate approach: $\underline{E}=\underline{\mathbf{Z} B}$, where $\underline{\mathbf{Z}}$ is the complex and frequency-dependent impedance tensor. In the following, the complex off-diagonal elements of $\underline{\mathbf{Z}}$, i.e. $Z_{x y}$ and $Z_{y x}$, are presented as apparent resistivities $\rho_{\mathrm{a}, x y}$ and $\rho_{\mathrm{a}, y x}$, and phases $\phi_{x y}$ and $\phi_{y x}$. The $x$ direction points towards east, the $y$ direction towards north; i.e. $\rho_{\mathrm{a}, y x}$ and $\phi_{y x}$ refer to magnetic field variations to the east and electric field variations to the north, which is the direction parallel to the ridge axis in the model.

Fig. 5 shows the apparent resistivities $\rho_{\mathrm{a}}$ and phases $\phi$ for different dynamic models at a site in the centre of the island directly above the plume where the effects are strongest. The high $\rho_{\mathrm{a}}$ values at short periods represent the high resistivity near the surface. Towards longer periods, the wavefields penetrate into the deeper, less resistive parts of the model. For the DPRM, the $\rho_{\mathrm{a}}$ decreases from $700 \Omega \mathrm{m}$ at a period of $10 \mathrm{~s}$ to $30 \Omega \mathrm{m}$ for $\rho_{\mathrm{a}, x y}$ and $60 \Omega \mathrm{m}$ for $\rho_{\mathrm{a}, y x}$ at the longer period end. The difference results from the 2-D structure of the ridge. The phases accordingly show a maximum of $c a 70^{\circ}$ at periods of $20 \mathrm{~s}$ and then decrease to $45^{\circ}$ and below, also differing slightly as a result of the 2-D ridge structure.

For different excess temperatures $\Delta T_{\mathrm{P}}(50,135,220 \mathrm{~K})$ all the curves look very similar. However, significant differences occur for varying melt fractions: at periods between $10-50 \mathrm{~s}$ the phases of the models differ by roughly $10^{\circ}$ between $\varphi_{\text {ex }}=0.1$ and 3 per cent. This leads to a stronger decrease of the resistivities in this period range resulting in a difference of a factor 4 at the longer periods. Extreme values are given for the model without extraction (maximum $\varphi=28$ per cent) with phases shifted upwards by up to $15^{\circ}$ and $\rho_{\mathrm{a}}$ decreased by an order of magnitude for the longer periods.

Fig. 6 presents the influence of the plume compared to that of the ridge in the transfer functions for $\varphi_{\mathrm{ex}}=1$ per cent, 3 per cent and no extraction. Again the largest differences occur for no extraction, but more interesting are the other two cases: for $\phi_{x y}$, there are only slight differences of $4^{\circ}$ at most for $\varphi_{\mathrm{ex}}=1$ per cent and differences up to $8^{\circ}$ for $\varphi_{\mathrm{ex}}=3$ per cent. For $\phi_{y x}$, the differences reach $12^{\circ}$ at periods $\leq 200 \mathrm{~s}$ being significant for both melt extractions. As in Fig. 5, the larger the phase, the stronger the decrease of the apparent resistivity with significantly different levels towards longer periods. Thus the plume is most likely detected from the MT transfer functions at $\phi_{y x}$ at periods around $200 \mathrm{~s}$. 

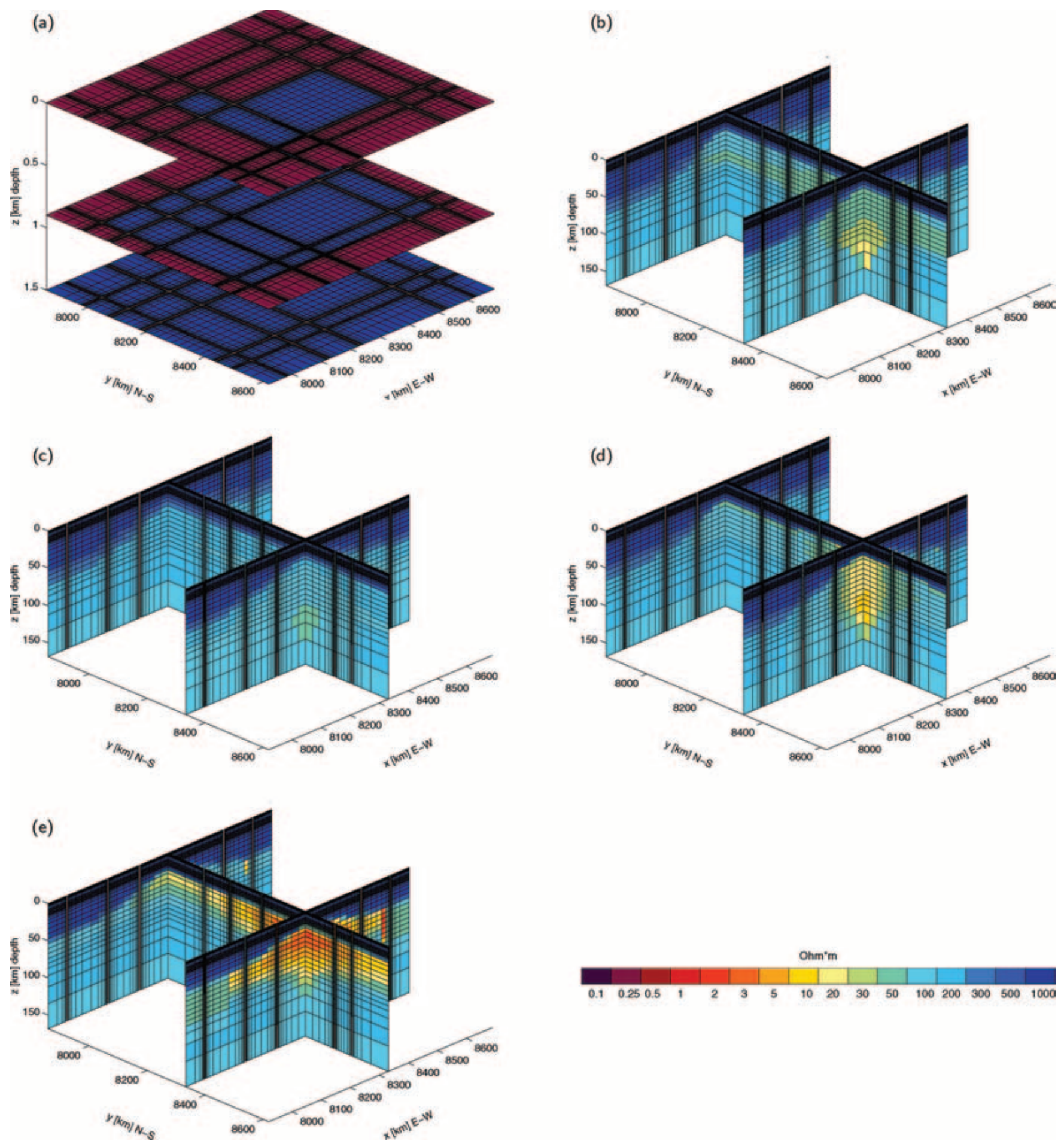

Figure 4. Resistivity distributions: (a) near-surface parts of the DPRM; (b) DPRM; (c) model 135-0.1; (d) model 135-3; (e) model without segregation/melt extraction. The $x$ and $y$ scales refer to the origin of the model coordinate system.

\subsection{Seismic velocities within a dynamic model of a ridge-centred plume}

Because the absolute temperature has to be used for calculating seismic velocity anomalies (cf. eq. 5) a reference temperature-depth profile has to be specified. We use a profile through the mantle taken at some distance from the plume (at $y=0$ ) at an $x$ position corresponding to a $20 \mathrm{Myr}$ old lithosphere. Thus all our seis- mic anomalies are taken with respect to a 20 Myr old lithosphere/ mantle.

Fig. 7(a) shows the seismic anomalies of the DPRM in a vertical cross-section through the plume. In Fig. 8(a), the $135 \mathrm{~K}$ curve shows a vertical profile through the plume centre. While the temperature effect within the plume stem leads to a reduction of $V_{S}$ of approximately -2 per cent, the combined temperature and melt effect reduces $V_{S}$ in the plume head by as much as -9 per cent. Recall- 

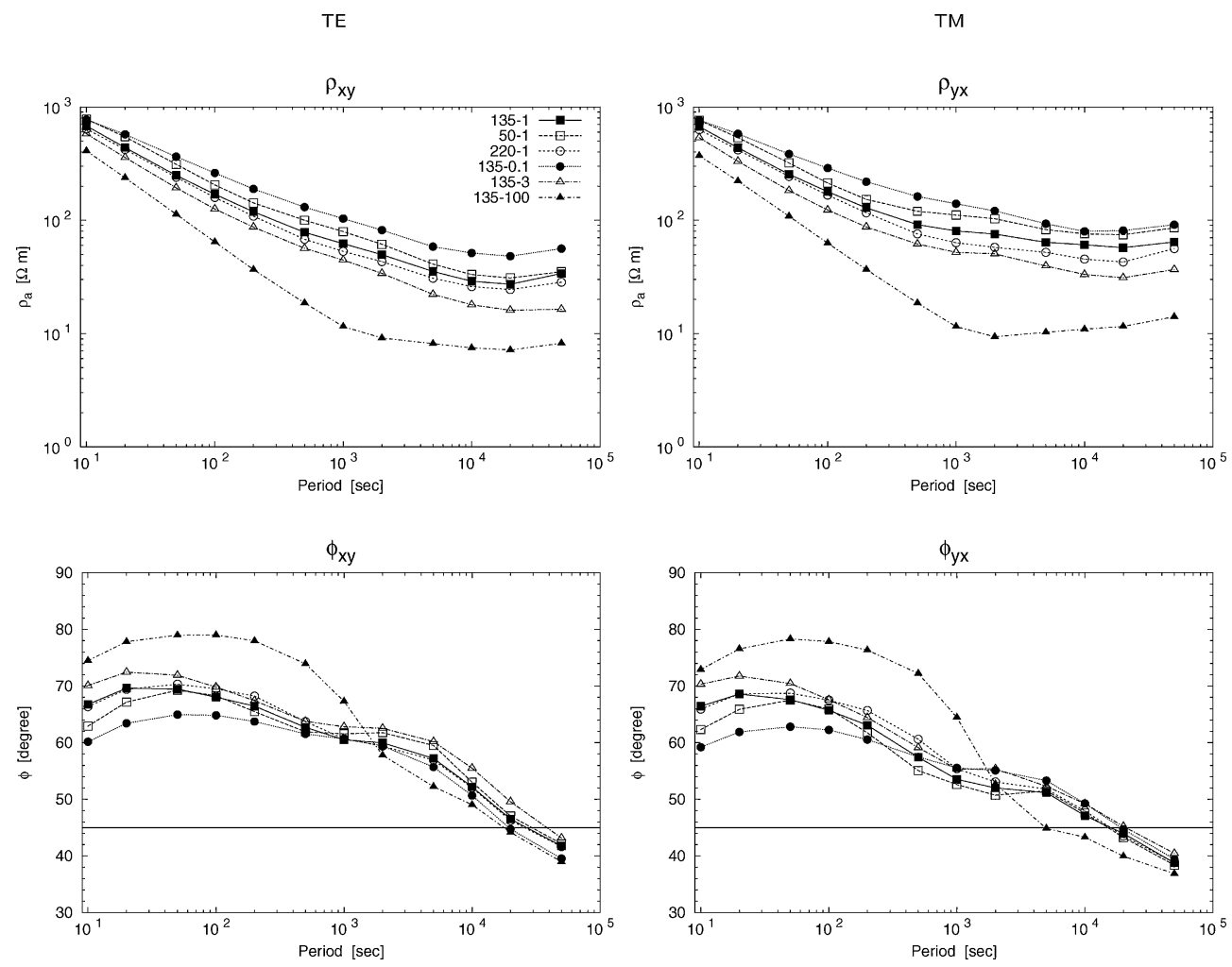

Figure 5. $x y$ and $y x$ components of the apparent resistivities $\rho_{\mathrm{a}}$ and phases $\phi$ for all models.
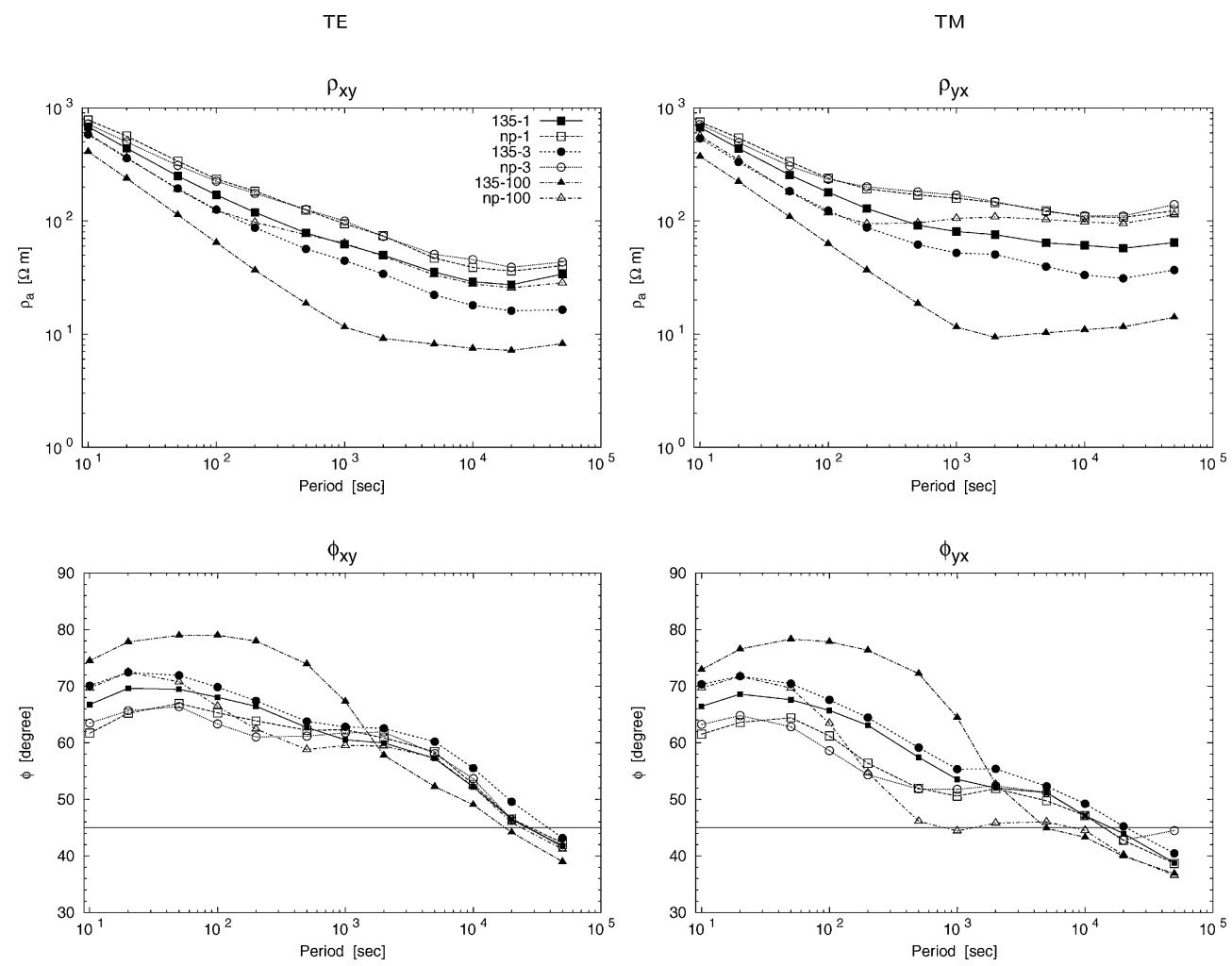

Figure 6. $x y$ and $y x$ components of the apparent resistivities $\rho_{\mathrm{a}}$ and phases $\phi$ for selected models with and without a plume, whereby np in the legend denotes no plume.

ing that the melt fraction hardly exceeds the extraction threshold of 1 per cent, eq. (10) reveals that within the shallow plume/ridge region essentially the high temperatures contribute to the strong anomalies (by up to -8 per cent). This strong temperature effect can be under- stood when it is realized that we compare shallow plume and ridge temperatures of up to approximately $1400{ }^{\circ} \mathrm{C}$ at 20 to $50 \mathrm{~km}$ model depth to a 20 Myr lithosphere, which has a temperature of 800 to $1000{ }^{\circ} \mathrm{C}$ at the same depth. Indeed, this effect already leads to a 

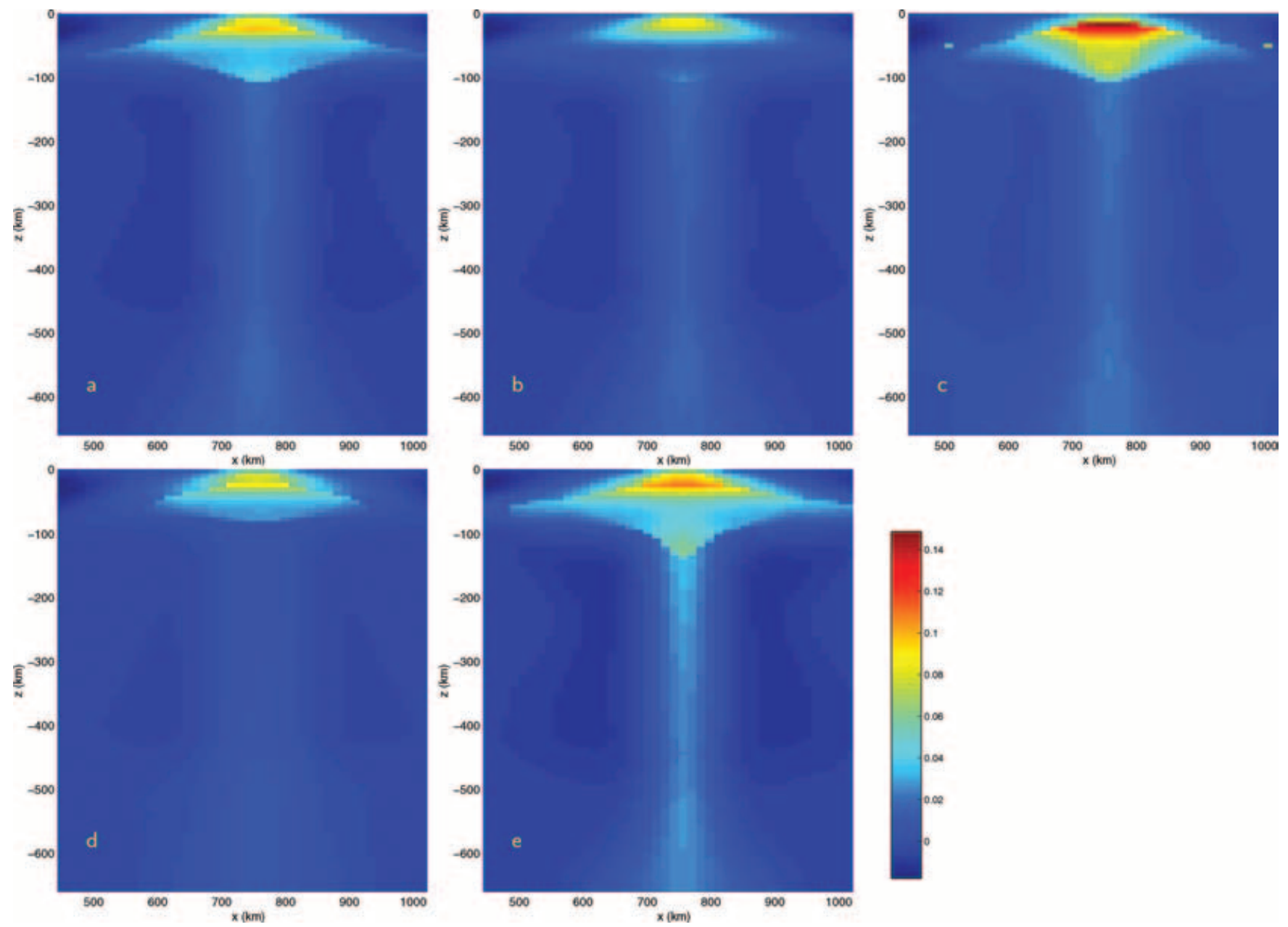

Figure 7. $-\delta V_{S} / V_{S}$ sections perpendicular to the ridge for 135-1 (a), 135-0.1 (b), 135-3 (c), 50-1 (d) and 220-1 (e). The effect of melting is visible by the sharp contrasts.
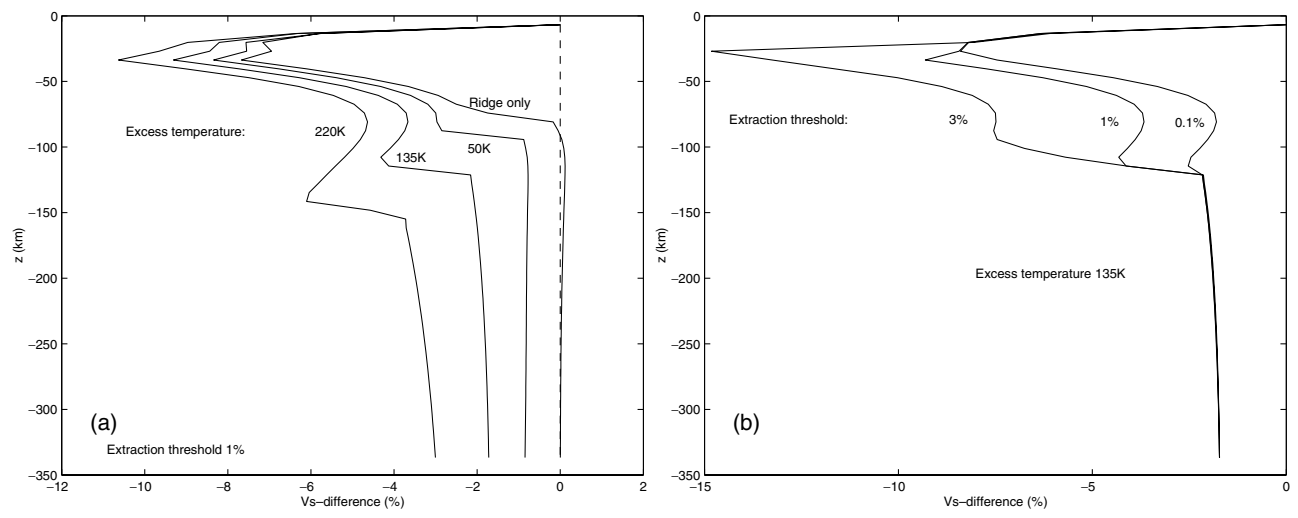

Figure 8. (a) Depth profiles of $\delta V_{S} / V_{S}$ in per cent at the plume centre for 50-1, 135-1 and 220-1, and at the normal ridge; (b) depth profiles of $\delta V_{S} / V_{S}$ in per cent at the plume centre for 135-0.1, 135-1 and 135-3. The effect of melting is visible by the kinks between 150 and $100 \mathrm{~km}$ depth.

strong anomaly (up to -7 per cent) of the ridge alone, as demonstrated by the ridge only curve in Fig. 8(a). Comparing the ridge only curve with the plume curve (DPRM, i.e. the $135 \mathrm{~K}$ curve in Fig. 8a) shows that the plume contribution to the total anomaly is not larger that -5 per cent. The effect of the plume is strongest at a depth of approximately $100 \mathrm{~km}$. Furthermore, the plume significantly increases the width of the $V_{S}$ anomaly zone (up to $500 \mathrm{~km}$ for the DPRM, Fig. 7a) compared with the ridge only (which has a width of approximately only $200 \mathrm{~km}$ in our simulations).

The effect of different extraction thresholds, i.e. melt fractions, is shown in Figs 7(b) and (c) (and accordingly Fig. 8b). While the seismic anomaly of the plume stem is not affected, the anomalies in the plume head are clearly dependent on the melt fraction. For nearly immediate melt extraction ( 0.1 per cent threshold, fractional 
melting), the $V_{S}$ anomaly represents essentially the temperature signal. It reveals that as a result of cooling by consumption of latent heat, the $V_{S}$ anomaly first decreases in the lower part of the plume head. Increasing the extraction threshold to 3 per cent leads to a progressive increase of melt fraction from 0 to 3 per cent between 122 and $86 \mathrm{~km}$ depth, which corresponds to a strong increase in $V_{S}$ anomaly.

The effect of different plume excess temperatures is shown in Figs 7(d) and (e) (and accordingly Fig. 8a). Although the excess temperature decreases to approximately 50 per cent of its initial value during the ascent through the upper mantle (see Paper I), the seismic anomalies increase towards shallower depths. Clearly both the plume stem and plume head are affected by the different temperatures. The colder plume stem hardly shows up as a seismic anomaly, the hot plume produces a significant anomaly within the plume stem.

Inspecting the different plume profiles in Fig. 8(b) reveals an interesting double low-velocity zone (LVZ) for the two hotter plumes (one in $33 \mathrm{~km}$ and one in 105 or $133 \mathrm{~km}$ depth, respectively). The deeper LVZ is a consequence of the onset of melting. However, the amplitude of the anomaly decreases upon further plume ascent because progressive melting cools the plume as a result of consumption of latent heat, while melt extraction keeps the melt fraction constant above the lower peak. At shallower depth this effect is outpaced by hot plume temperatures compared with the reference lithosphere and a second, stronger anomaly produces the shallower LVZ. If the melt fraction is higher ( 3 per cent, Fig. 8a), the melt effect overprints the double LVZ and leads to one strong LVZ with a maximum anomaly of almost -15 per cent.

\section{DISCUSSION}

\subsection{Evaluating the possibility of detecting the Iceland plume with MT data}

All plume models reduce the mantle resistivity only slightly compared with a normal ridge setting. MT signals can only identify the presence of a mantle plume at low depth ( $c$ a 50-120 km). Thus, for the models with $\varphi_{\mathrm{ex}}=0.001$ and also with $\varphi_{\mathrm{ex}}=0.01$, the effect of the ridge prevails even on the most promising location above the plume centre. The small differences in the transfer functions between the corresponding models including and not including the plume are obvious (Fig. 6). In real field data, such small deviations would probably lie within the error limits. These small differences further decrease if we take into account a mantle depletion as a result of the melting process (Fig. 2). As a result of depletion, the solid rock conductivity decreases and lowers the resulting effective conductivity in the plume significantly.

For $\varphi_{\mathrm{ex}}=0.03$, the situation changes. The distinction between ridge and plume signal becomes stronger (Fig. 6) and reaches observable values. Even in the case of mantle depletion, the strong signal from the plume holds, because the amount of high conducting melt is sufficient to provide observable high effective conductivities. Therefore, a significant decrease in the apparent resistivity and corresponding values for the phase at periods larger than $1000 \mathrm{~s}$ (cf. Figs 5 and 6) will indicate the existence of the plume with the melt fraction in the corresponding depth exceeding 3 per cent.

Unfortunately for MTs, we cannot show comparisons between these models and real data yet. Since 1999, long-period MT measurements have been carried out on Iceland. First analyses were made by König (1999) and Salat (2002) for three sites but the data have to be analysed more intensely, especially with respect to the influence of varying source geometries of the polar electrojet. Another problem is the need for long-lasting time segments of continuous recording of the electric and magnetic field variations; instrumental failures often led to time segments too short to use them for long-period statistics. However, the still ongoing measurements are promising and will provide MT transfer functions for periods up to 50000 or $100000 \mathrm{~s}$.

The models discussed in this paper show transfer functions based on maximum contrasts for the chosen parameters. Real rocks probably will more likely show gradients instead of distinct transitions between different conductivities. Furthermore, additional good conducting layers in the crust or the upper mantle will decrease the penetration depth of the electromagnetic waves and lead to a worse resolution. As shown by Beblo \& Björnsson (1978, 1980), Beblo et al. (1983) and Eysteinsson \& Hermance (1985) beneath wide areas of Iceland a high conducting zone exists in the crust (at around $10 \mathrm{~km}$ depth) that was not considered in this paper. The observed apparent resistivities at some relevant sites show a distinct minimum (and a corresponding phase) at periods between 70 and $120 \mathrm{~s}$. Therefore, the shape of the transfer functions shown in this paper will change if considering such a conducting layer. Then the signal from the mantle plume will be less significant unless the melt fraction is above 3 per cent.

\subsection{Comparison with seismological observations}

It is interesting to compare our predicted seismic velocity anomalies with seismological observations of the Iceland plume. Teleseismic traveltime anomalies have been inverted for the 3-D mantle structure beneath the Iceland region by Wolfe et al. (1997). The solutions show a cylindrical LVZ with a diameter of approximately $300 \mathrm{~km}$ that extends from 100 to at least $400 \mathrm{~km}$ depth beneath central Iceland. The magnitude of the anomaly is approximately -2 to -4 per cent for $S$ waves. Based on a 35-station network of broad-band seismometers of the Iceland HOTSPOT project, Foulger et al. (2001) were able to resolve the anomalies between 60 and $450 \mathrm{~km}$ depth. $V_{S}$ amplitudes of up to -4.9 per cent were found within a low-velocity conduit with a diameter of 200 to $250 \mathrm{~km}$. The smaller horizontal extent of $200 \mathrm{~km}$ is in agreement with results on the basis of apparent attenuation observations by Allen et al. (1999). In a recent study by Allen et al. (2002), the Iceland HOTSPOT project data set has been complemented by the SIL and ICEMELT data (Bjarnason et al. 1996) and local surface waves have been used to correct for crustal structures. As a result, a maximum $V_{S}$ anomaly of -3.8 per cent has been found in a pseudo-cylindrical structure, slightly elongated in a north-south direction. Finite frequency traveltime tomography, which accounts for seismic wave front healing, seems to indicate that $S$ velocity perturbations may be approximately 1-2 times larger than the results based on ray theory alone (Hung et al. 2003). From these studies, an expected range of $S$ velocity anomalies within the plume stem may be estimated, which is plotted as a box in Fig. 9 for comparison with the modelled velocities. At first sight, high plume excess temperatures of approximately 220 $\mathrm{K}$ at 150 to $300 \mathrm{~km}$ depth may explain the tomographic data. If, however, the observations represent a lower bound because of wave front healing effects, even higher excess temperatures (180 to 360 $\mathrm{K})$ are needed. Before an alternative interpretation is presented, we have to focus our attention to the plume head region.

The regional tomographic models discussed so far are based on stations on land only and do not seem to reveal the shallow, laterally extended structure of the expected spreading plume head. Allen 


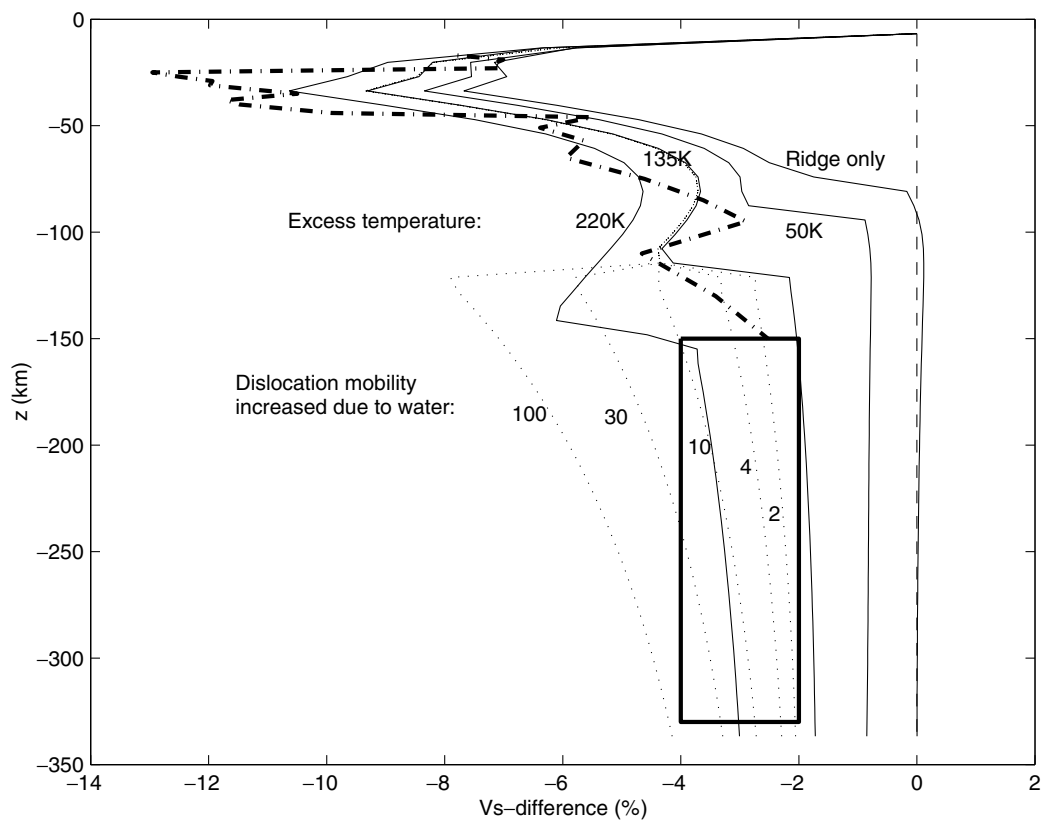

Figure 9. Comparison of the modelled depth profiles of $\delta V_{S} / V_{S}$ in per cent at the plume centre for the models 50-1, 135-1, 220-1 and the normal ridge with seismological observations. Dashed-dotted curve results from surface wave inversions in central Iceland (Bjarnason \& Sacks 2002), the rectangle gives the range of seismic tomography studies. The dotted curves show the effect of water for the model 135-1, amplifying the velocity anomaly by increasing the mobility of dislocations.

et al. (2002) used long-period teleseismic surface waves to constrain the average structure of the uppermost mantle of their model. Thus, their composite seismic model of the Iceland plume consists of a narrow plume stem $\left(200 \mathrm{~km},-3.8\right.$ per cent $V_{S}$ anomaly) overlain by a plume head with a $V_{S}$ anomaly increasing from -3 per cent (180 km depth) to -8 per cent ( $50 \mathrm{~km}$ depth). Inversions of Rayleigh and Love waves generated by regional earthquakes on the Reykjanes and Kolbeinsey ridges (including the Jan Mayen fracture zone) have been carried out for different path segments on Iceland by Bjarnason \& Sacks (2002). The seismic anisotropy structure of Iceland is not completely constrained, but results from shear wave splitting (Bjarnason et al. 2002) suggest that a north-south Rayleigh wave path through the plume centre is in the direction of the azimuthal averaged velocity. When subtracting the inverted $S V$ velocities from a profile representing a $20 \mathrm{Myr}$ old lithosphere-asthenosphere part of the Iceland plateau (the area between the Jan Mayen transform fault and Iceland; Evans \& Sacks 1979), somewhat higher asthenospheric $S$ velocity anomalies ( -10 to -12 per cent between 25 and $45 \mathrm{~km}$, decreasing to approximately -4.5 per cent at $110 \mathrm{~km}$ depth) are present beneath central Iceland (Fig. 9, dashed-dotted curve). The uppermost part of the inverted LVZ might be partly affected by comparing crustal velocities in Iceland with mantle velocities beneath the Iceland plateau. A second LVZ at $110 \mathrm{~km}$ depth seems to be a robust feature of the inversion.

Comparing the dashed-dotted curve with the model results suggest that plume excess temperatures of $135 \mathrm{~K}$ at $200 \mathrm{~km}$ depth and roughly 1 per cent melt extraction threshold could explain the central Iceland data. Somewhat higher melt fractions ( 2 per cent) might be possible in the upper part of the plume head (cf. Fig. 9). Interestingly, the second, deeper LVZs of the $S$ inversions and the model agree well in position and amplitude.

Obviously the inferred moderate plume head excess temperature $\left(\Delta T_{\mathrm{P}}=135 \mathrm{~K}\right)$ and the hot plume stem $(>220 \mathrm{~K}$ at $200 \mathrm{~km}$ depth $)$ do not fit together. Furthermore, the hot plume has been discarded in Paper I because it produces an unrealistic crustal thickness. One possible way to reconcile these findings is to incorporate water into the plume. Karato \& Jung (1998) have argued that small amounts of water affect seismic velocities of olivine not directly by the reduction of bond strength, but indirectly by increasing the mobility of defects such as dislocations, i.e. by increasing seismic wave attenuation. The water-enhanced increase in mobility can be accounted for by inserting a factor $M^{q}$ into eq. (6) (Karato \& Jung 1998), where $M=1$ for dry conditions and $M>1$ gives the amplification of dislocation mobility as a result of water (i.e. the increase in strain rate in creep experiments). Based on laboratory experiments at $300 \mathrm{MPa}$ ambient pressure, Hirth \& Kohlstedt (1996) propose a linear relationship between $M$ and the water concentration $C_{\mathrm{OH}}$ dissolved in olivine of approximately $M=0.56 C_{\mathrm{OH}}\left(C_{\mathrm{OH}}\right.$ in ppm $\mathrm{H} / \mathrm{Si}$ ). Assuming that the plume contains small amounts of water, while the reference mantle is dry, the dotted curves show the effect of water on the $135 \mathrm{~K}$ plume (Fig. 9). A 10-fold dislocation mobility increase is sufficient to raise the anomaly to observed values, higher values (30 to 100) are needed if the seismic anomaly turns out to be stronger. Upon melting, most of the water will be dissolved in the melt being extracted, leaving behind an essentially dry plume head. Thus seismic anomalies in the plume head are characterized essentially by a dry partially molten mantle, while the plume stem may be wet.

The effect of water on melting is to reduce the solidus. The onset of melting is shifted downward, but the degree of melting is small for temperatures between the wet solidus and dry solidus. Thus, the contribution of hydrous melts to the total volume of melts is small in the plume as well as under mid-oceanic ridges and will not result in a significant increase of crustal thickness. Furthermore, stiffening of the mantle by dehydration of the matrix is known to reduce active upwelling in the melting parts of the plume (Ito et al. 1999) and will thus rather reduce melt production in it, leading to a thinner crust; however, hydrous melting would have to be modelled explicitly in 
order to make quantitative predictions, which is beyond the scope of this paper. However, it has to be noted that water and also anisotropy may lead to changes in the estimated seismic and MT characteristics shown in this paper.

Another interesting point is that the modelled velocity decrease is similar to the velocity decrease as a result of ellipsoidal inclusions of aspect ratio 0.05 to 0.1 or of tubular channels (Mavko 1980; Schmeling 1985b). These aspect ratios are one order of magnitude higher than those calculated for the electrical conductivities ( $c f$. Table 3). As one possibility, this inconsistency can be explained with a bimodal melt distribution, e.g. melt pockets connected through strongly elongated ellipses or films, and how seismic and electromagnetic waves respond to melt inclusions: a reduction of seismic velocities is mainly caused by large melt pockets, which do not have to be connected necessarily, whereas MTs is sensitive to laterally expanded conductors, i.e. connected melt inclusions or films. Alternatively, the higher aspect ratios of the seismic model could be used for the electrical conductivity models. Then the modelled extraction threshold would correspond to a melt distribution of reduced connectivity, and the effect of melt on electrical conductivity would be smaller. In this case, the resistivities shown in Fig. 4 would represent lower bounds.

\section{CONCLUSIONS}

The synthetic observables from the geodynamic modelling and the available observations lead to the following conclusions concerning the plume:

(i) the appropriate plume excess temperature $\Delta T_{\mathrm{P}}$ at $200 \mathrm{~km}$ depth is $135 \mathrm{~K}$;

(ii) the suitable melt extraction threshold $\varphi_{\mathrm{ex}}$ is 1 per cent.

These values explain crustal thicknesses of Iceland and the normal ridge and Iceland seismic observations of the plume head. Increasing $\Delta T_{\mathrm{P}}$ to $220 \mathrm{~K}$ demands higher $\varphi_{\mathrm{ex}}$ (3 per cent) to get reasonable crustal thicknesses above the plume region; however, in this case, no normal oceanic crust is generated. Lower $\Delta T_{\mathrm{P}}$ and $\varphi_{\mathrm{ex}}$ create model data that do not explain the seismic observations for the plume head. However, the inferred moderate plume head excess temperature $(135 \mathrm{~K})$ does not explain the seismic plume stem data.

(i) To fit the seismic data in the plume stem, a small amount of water is incorporated into the plume, causing a dry plume head and a wet stem. This will not influence the MT data, because the lateral extent of the plume stem is too small compared with its depth.

(ii) If the plume head contains only 1 per cent of melt, the MT transfer functions cannot resolve the additional plume signal in this special case of a ridge-plume interaction. A significant influence is not observed until the melt extraction threshold $\varphi_{\text {ex }}$ amounts to at least 3 per cent.

(iii) The chosen values for the plume excess temperature $\Delta T_{\mathrm{P}}$ and the melt extraction threshold $\varphi_{\text {ex }}$ lead to a vertical velocity of the plume of $13 \mathrm{~cm} \mathrm{yr}^{-1}$ at the bottom of the melting zone.

(iv) The mantle rock depletion has only small influence on the seismic and MT data.

\section{ACKNOWLEDGMENTS}

This research was supported by the Deutsche Forschungsgemeinschaft, grants Schm 872/6-1 and Schm 872/6-2. We wish to thank Wolfgang Jacoby for helpful and inspiring discussions, Thomas J.
Shankland and an anonymous referee for valuable comments and constructive criticism.

\section{REFERENCES}

Allen, R.M. et al., 1999. The thin hot plume beneath Iceland, Geophys. J. Int., 137(1), 51-63.

Allen, R.M. et al., 2002. Imaging the mantle beneath Iceland using integrated seismological techniques, J. geophys. Res., 107(12), 2325, doi: 10.1019/2001JB000595.

Beblo, M. \& Björnsson, A., 1978. Magnetotelluric investigation of the lower crust and upper mantle beneath Iceland, J. Geophys., 45, 1-16.

Beblo, M. \& Björnsson, A., 1980. A model of electrical resistivity beneath NE-Iceland, correlation with temperature, J. Geophys., 47, 184-190.

Beblo, M., Björnsson, A., Arnason, K., Stein, B. \& Wolfgram, P., 1983. Electrical conductivity beneath Iceland - constraints imposed by magnetotelluric results on temperature, partial melt, crust and mantle structure, J. Geophys., 53, 16-23.

Berckhemer, H., Kampfmann, W. \& Aulbach, E., 1982. Anelasticity and elasticity of mantle rocks near partial melting, in High-Pressure Researches in Geoscience, pp. 113-132, ed. Schreier, W., Schweizerbart'sche Verlagsbuchhandlung, Stuttgart, Germany.

Bijwaard, H. \& Spakman, W., 1999. Tomographic evidence for a narrow whole mantle plume below Iceland, Earth planet. Sci. Lett., 166, 121126.

Bjarnason, I.T. \& Sacks, I.S., 2002. The plume, lithosphere and asthenosphere of Iceland, in Geophysical Research Abstracts, Vol. 4, p. 5557, European Geophysical Society.

Bjarnason, I.T., Wolfe, C.J., Solomon, S.C. \& Gudmundsson, G., 1996. Initial results from the ICEMELT experiment: Body-wave delay times and shear-wave splitting across Iceland, Geophys. Res. Lett., 23(5), 459-461, correction in, Geophys. Res. Lett., 23(8), 903.

Bjarnason, I.T., Silver, P.G., Rümpker, G. \& Solomon, S.C., 2002. Shearwave splitting across the Iceland hotspot: Results from the ICEMELT experiment, J. geophys. Res., 107(B12), 2382, doi:10.1029/2001JB000916

Christensen, N.I., 1989. Seismic velocities, in CRC Practical Handbook of Physical Properties of Rocks and Minerals, pp. 429-546, ed. Carmichael, R.S., CRC Press, Boca Raton, FL.

Constable, S., Shankland, T.J. \& Duba, A., 1992. The electrical conductivity of an isotropic olivine mantle, J. geophys. Res., 91(B3), 3397-3404.

Darbyshire, F.A., White, R.S. \& Priestley, K.F., 2000. Structure of the crust and uppermost mantle of Iceland from a combined seismic and gravity study, Earth planet. Sci. Lett., 181, 409-428.

Evans, J.R. \& Sacks, I.S., 1979. Deep structure of the Iceland plateau, J. geophys. Res., 84, 6859-6866.

Eysteinsson, H. \& Hermance, J.F., 1985. Magnetotelluric measurements across the eastern neovolcanic zone in south Iceland, J. geophys. Res., 90, $10093-10103$.

Faul, U.H., 1997. The permeability of partially molten upper mantle rocks from experiments and percolation theory, J. geophys. Res., 102(B5), 10 299-10311.

Foulger, G.R. et al., 2001. Seismic tomography shows that upwelling beneath Iceland is confined to the upper mantle, Geophys. J. Int., 146(2), 504530 .

Goes, S.R., Govers, R. \& Vacher, P., 2000. Shallow mantle temperatures under Europe from $\mathrm{P}$ and $\mathrm{S}$ wave tomography, J. geophys. Res., 105, 11 153-11 169.

Hammond, W.C. \& Humphreys, E.D., 2000. Upper mantle seismic wave velocity: Effects of realistic partial melt geometries, J. geophys. Res., 105(B5), 10 975-10986.

Hashin, Z. \& Shtrikman, S., 1963. A variational approach to the theory of the elastic behaviour of multiphase materials, J. Mech. Phys. Solids, 11, 127-140.

Hersir, G.P., Björnsson, A. \& Pedersen, L.B., 1984. Magnetotelluric survey across the active spreading zone in southwest Iceland, J. Volc. Geoth. Res., 20, 253-265. 
Hirth, G. \& Kohlstedt, D.L., 1996. Water in the oceanic upper mantle: implications for rheology, melt extraction and the evolution of the lithosphere, Earth planet. Sci. Lett., 144, 93-108.

Hung, S.-H., Shen, Y. \& Chiao, L.-Y., 2003. Imaging the Iceland mantle plume by finite frequency traveltime tomography, in Geophysical Research Abstracts, p. 11 076, European Geophysical Society.

Ito, G., Shen, Y., Hirth, G. \& Wolfe, C.J., 1999. Mantle flow, melting and dehydration of the Iceland mantle plume, Earth planet. Sci. Lett., 165, 81-96.

Jackson, I., Fitz Gerald, J.D., Faul, U., Kokkonen, H., Carr, J. \& Tan, B., 2000. Seismic wave attenuation in polycrystalline olivine: frequency, temperature and grainsize sensitivity, in Annual Report, pp. 115-117, ANU, Canberra, Australia.

Jordan, T.H., 1979. Mineralogies, densities and seismic velocities of garnet lherzolites and their geophysical implications, in The mantle Sample: Inclusions in Kimberlites and other Volcanics, pp. 1-14, eds Boyd, F. \& Meyer, O., American Geophysical Union, Washington, DC.

Karato, S.-I., 1993. Importance of anelasticity in the interpretation of seismic anisotropy, Geophys. Res. Lett., 20, 1623-1626.

Karato, S.-I. \& Jung, H., 1998. Water, partial melting and the origin of the seismic low velocity and high attenuation zone in the upper mantle, Earth planet. Sci. Lett., 157, 193-207.

König, M., 1999. Langzeitbeobachtung erdelektrischer und erdmagnetischer Felder in Island, MSc thesis, Ludwig-Maximilians-Universität, München.

Krajew, A.P., 1957. Grundlagen der Geoelektrik, VEB Verlag Technik, Berlin.

McKenzie, D. \& Bickle, M.J., 1988. The volume and composition of melt generated by extension of the lithosphere, J. Petrol., 29(3), 625-679.

Mackie, R.L., Smith, J.T. \& Madden, T.R., 1994. Three-dimensional electromagnetic modeling using finite difference equations: the magnetotelluric example, Radio Sci., 29, 923-935.

Madden, T.R., 1976. Random networks and mixing laws, Geophysics, 41, 1104-1125.

Maumus, J., Bagdassarov, N. \& Schmeling, H., 2004. Electrical conductivity and partial melting of mafic rocks under pressure, Geochim. Cosmochim. Acta., submitted.

Mavko, G.M., 1980. Velocity and attenuation in partially molten rocks, $J$. geophys. Res., 85, 5173-5189.

O’Connell, R.J. \& Budiansky, B., 1977. Viscoelastic properties of fluidsaturated cracked solids, J. geophys. Res., 82, 5719-5735.

Rhodes, M. \& Davies, J.H., 2001. Tomographic imaging of multiple mantle plumes in the uppermost lower mantle, Geophys. J. Int., 147, 88-92.

Ritsema, J., van Heijst, H.J. \& Woodhouse, J.H., 1999. Complex shear wave velocity structure imaged beneath Africa and Iceland, Science, 286, 19251928.

Roberts, J.J. \& Tyburczy, J.A., 1999. Partial-melt electrical conductivity: influence of melt compositions, J. geophys. Res., 104, 7055-7065.

Ruedas, T., Schmeling, H., Marquart, G., Kreutzmann, A. \& Junge, A., 2004. Temperature and melting of a ridge-centred plume with application to Iceland, Part I: Dynamics and crust production, Geophys. J. Int., 158, 729-743 (Paper I).

Salat, C., 2002. Bearbeitung von Magnetotellurik-Daten aus Langzeitmessungen auf Island, MSc thesis, Ludwig-Maximilians-Universität, München.

Sato, H., Sacks, I.S., Murase, T., Muncill, G. \& Fukuyama, H., 1989. $Q p-$ melting temperature relation in peridotite at high pressure and temperature: Attenuation mechanism and implications for the mechanical properties of the upper mantle, J. geophys. Res., 94(B8), 10 647-10 661.

Schmeling, H., 1985a. Partial melt below iceland: A combined interpretation of seismic and conductivity data, J. geophys. Res., 90, 10 105-10 116.

Schmeling, H., 1985b. Numerical models on the influence of partial melt on elastic, anelastic, and electric properties of rocks. Part I: elasticity and anelasticity, Phys. Earth planet. Int., 41, 34-57.

Schmeling, H., 1986. Numerical models on the influence of partial melt on elastic, anelastic, and electric properties of rocks. Part II: electrical conductivity, Phys. Earth planet. Int., 43, 123-136.

Shankland, T.J. \& Waff, H.S., 1977. Partial melting and electrical conductivity anomalies in the upper mantle, J. geophys. Res., 82, 5409-5417.
Sobolev, S.V., Zeyen, H., Stoll, G., Werling, F., Altherr, R. \& Fuchs, K., 1996. Upper mantle temperature from teleseismic tomography of French Massif Central including effects of composition, mineral reactions, anharmonicity, anelasticity and partial melt, Earth planet. Sci. Lett., 139, $147-163$.

Takei, Y., 1998. Constitutive mechanical relations of solid-liquid composites in terms of grain-boundary contiguity, J. geophys. Res., 103(B8), 18183 18204.

Takei, Y., 2000. Acoustic properties of partially molten media studied on a simple binary system with a controllable dihedral angle, J. geophys. Res., 105(B7), $16665-16682$.

Tryggvason, K., Husebye, E. \& Stefánsson, R., 1983. Seismic image of the hypothesized Icelandic hot spot, Tectonophysics, 100, 97-118.

Tyburczy, K.A. \& Fisler, D.K., 1995. Electrical properties of minerals and melts, in Mineral Physics and Crystallography, pp. 185-208, ed. Ahrens, T., American Geophysical Union, Washington, DC.

Tyburczy, K.A. \& Waff, H.S., 1983. Electrical conductivity of molten basalt and andesite to 25 kilobars pressure: Geophysical significance and implications for charge transport and melt structure, J. geophys. Res., 88, 2413-2430.

Waff, H.S. \& Weill, D.F., 1975. Electrical conductivity of magmatic liquids; effects of temperature, oxygen fugacity and composition, Earth planet. Sci. Lett., 28, 254-260.

White, R.S. \& McKenzie, D.P., 1995. Mantle plumes and flood basalts, J. geophys. Res., 100(B9), 17543-17585.

Widmer, R., Masters, G. \& Gilbert, F., 1991. Spherically symmetric attenuation within the earth from normal mode data, Geophys. J. Int., 104, $541-553$.

Wolfe, C.J., Bjarnason, I.T., VanDecar, J.C. \& Solomon, S., 1997. Seismic structure of the Iceland mantle plume, Nature, 385, 245-247.

Zippel, R., 1996. Numerische Modellierung der elastischen Eigenschaften partiell geschmolzener Gesteine, MSc thesis, Johann Wolfgang GoetheUniversität, Frankfurt am Main.

\section{APPENDIX A: DERIVATION OF THE EFFECTIVE CONDUCTIVITY LAW}

In the model of Schmeling (1986), the melt phase forms axisymmetric spheroidal inclusions of random orientation. Depending on the aspect ratio $\mathcal{A}$ of these inclusions and the total number and volume of the inclusions (i.e. the melt fraction $\varphi$ ), the probability for overlapping of two neighbouring inclusions can be determined. Let $N$ be the number of inclusions within the neighbourhood of a melt inclusion that overlap with or are connected to the central inclusion, then $N_{\max }=4$ is the number of connected neighbours that define a fully connected system. Furthermore, the connectivity can be defined as

$P(\mathcal{A}, \varphi)=\left\{\begin{array}{cl}{[N(\mathcal{A}, \varphi)] /\left(N_{\max }\right),} & N \leq N_{\max } \\ 1, & N>N_{\max }\end{array}\right.$

The quantity $N$ depends on the melt fraction and the aspect ratio and has been empirically determined by Schmeling (1986):

$N(\mathcal{A}, \varphi)=\left(5.65+\frac{1.72}{\mathcal{A}}\right) \varphi$,

with $\mathcal{A} \leq 1$. If $N=0$, the inclusions are isolated. The effective conductivity of a system containing randomly oriented isolated ellipsoidal inclusions, $\sigma_{\text {iso }}$, has been determined by Krajew (1957):

$\sigma_{\text {iso }}=\frac{1}{3}\left(\sigma_{1}+\sigma_{2}+\sigma_{3}\right)$,

where

$\sigma_{i}=\sigma_{\mathrm{s}} \frac{(1-\varphi)\left(n_{i}-1\right) \sigma_{\mathrm{s}}+\left(n_{i}-\left(n_{i}-1\right)(1-\varphi)\right) \sigma_{\mathrm{f}}}{\left(n_{i}-1+\varphi\right) \sigma_{\mathrm{s}}+(1-\varphi) \sigma_{\mathrm{f}}}$, 
$i=1,2,3$, and $\sigma_{\mathrm{s}}$ and $\sigma_{\mathrm{f}}$ are the conductivities of solid mantle rock and melt, respectively.

$n_{1}=n_{2}=\frac{-2 h^{3}}{h-\left(1+h^{2}\right) \cot h}$,

$n_{3}=\frac{-h^{3}}{\left(1+h^{2}\right)(\cot h-h)}$,
$h=\sqrt{\mathcal{A}^{-2}-1}$.

If $N>4$, the melt phase is fully connected and the effective conductivity can be approximated by the upper Hashin-Shtrikman bound $\sigma_{\mathrm{HS}+}($ Hashin \& Shtrikman 1963):

$\sigma_{\mathrm{HS}+}=\sigma_{\mathrm{f}}+(1-\varphi)\left(\frac{1}{\sigma_{\mathrm{s}}-\sigma_{\mathrm{f}}}+\frac{\varphi}{3 \sigma_{\mathrm{f}}}\right)^{-1}$. 